\title{
Human scent samples for chemical analysis
}

\author{
Petra Pojmanová ${ }^{1}$ · Nikola Ladislavová ${ }^{1}$. Veronika Škeř́ková ${ }^{1} \cdot$ Patrik Kania ${ }^{1}$ S Štěpán Urban ${ }^{1}$
}

Received: 25 June 2019 / Accepted: 4 November 2019 / Published online: 9 November 2019

(c) The Author(s) 2019

\begin{abstract}
This study is focused on finding an optimal preparation of the human scent samples for their detailed chemical analysis in connection with the possible forensic identifications of human individuals in the future. At the present time, the scent identification of people is carried out nearly exclusively using specially trained dogs. It is assumed that the human scent contains a certain group of compounds which allows the identification of people, the so-called human scent signature; however, its chemical composition is completely unknown, as of now. The principal problem of human scent studies consists in the very low concentrations of thousands of the scent compounds, whereas their relative concentrations are usually dramatically different. It seems to be obvious that the most appropriate analytical technique for these thousands of different chemical compounds is GC/MS. However, it is also necessary to find the most suitable sorbent material for human scent collection, an extraction solvent, and a pre-concentration technique. The selection of the appropriate gas chromatographic method is also important to achieve the optimal resolution of the targeted compounds. Of course, in the first instance, it is necessary to decide what it means "the most suitable" for human scent chemical analysis.
\end{abstract}

Keywords Human scent analysis $\cdot$ GC-MS $\cdot$ Sample treatment $\cdot$ Extraction recovery

\section{Introduction}

The human skin scent is a complex chemical mixture of several thousands of more or less volatile organic compounds (VOCs) with dramatically different abundances, whereas the relative concentrations of some compounds significantly vary over time (Prada et al. 2014). It is assumed that the human skin scent contains the so-called primary as well as secondary parts. The primary part includes compounds whose relative concentrations are rather static, while the secondary part contains chemical compounds whose abundances depend on environmental factors, diet, weather, humidity, the visceral state, the emotional state, illnesses, the menstrual cycle, medication etc. (Curran et al. 2005). Besides these primary and secondary human scent parts, there are tertiary compounds that come from the external environment, e.g., from cosmetics, the scent of the

Petra Pojmanová

petra.pojmanova@vscht.cz

1 Department of Analytical Chemistry, Faculty of Chemical Engineering, University of Chemistry and Technology Prague, Technická 5, 16628 Prague, Czech Republic workplace, gasoline, smoking, domestic animals as well as the primary and secondary scents of other people.

Only several hundred chemical compounds of the human scent have been successfully described so far (de Lacy Costello et al. 2014). The human scent contains, e.g., alkanes, aldehydes, ketones, amines, alcohols, amides, fatty acids, and their esters (Doležal et al. 2017; Pandey and Kim 2011; Prada et al. 2010). The chemical analysis of such a complex mixture provides several thousands of different compounds, where some of them have distinctively varied concentrations and some of them have concentrations under the detection limits of any analytical chemistry instruments.

A key factor of this technique is the sampling material and its sorption properties. Many authors (DeGreeff et al. 2011; Hudson-Holness and Furton 2010; Prada et al. 2010, 2011) have engaged in a comparison of the sorption properties of textile materials, especially cotton, silk or polyester fibers. Their results indicate that the chemical properties of the materials, rather than their surface morphology, actually play a role in the ability of materials to capture and rerelease VOCs. In other studies, non-textile materials were used. Kusano et al. (2011) used sterile cotton-tipped applicators for buccal cells and saliva collection, a Teflon Bo-VOC ${ }^{\circledR}$ breath sampler for the collection of breath and a Whatman 
FTA ${ }^{\circledR}$ MiniCard for the collection of blood. Bernier et al. $(1999,2000)$ used glass beads.

A large number of studies, for example (Caroprese et al. 2009; Curran et al. 2010; DeGreeff et al. 2011; Prada et al. 2011; Syed and Leal 2009), used the SPME (Solid Phase Micro Extraction) method to transfer VOCs from textile materials. Some other studies (Haze et al. 2001; Natsch et al. 2006; Zeng et al. 1991, 1996) used extraction with various solvents to extract VOCs from textile materials. Gallagher et al. (2008) eliminated the sorbent from the sampling procedure completely. They applied the solvent mixture (ethanol/ hexane) directly to the skin with a special funnel. A comprehensive review of the collection methods can be found in the work of Dormont et al. (2013).

From the above-cited studies, it is obvious that the chemical analysis of the scent samples requires a highly sensitive technique as well as a scent collection method which minimalizes sample contaminations. In addition to this, the optimal method for the preparation of the scent samples must facilitate the chemical analysis not only of volatile scent compounds but also of chemical compounds that are less or very little volatile as they have a special significance for the scent identification method, but these compounds were marginalized in many previous studies. These little volatile scent compounds are probably preferred in the line-up scent identification procedure carried out by the specially trained dogs (Doležal et al. 2019).

\section{Experimental part}

\section{Chemicals and materials}

Hexane (in the quality for GC-MS), methanol (in the quality for LC-MS) and acetonitrile (in the quality for HPLC) were purchased from Sigma-Aldrich (USA). Ethanol (for UV-Vis spectroscopy, min. 99.8\%) was purchased from Penta \{Czech Republic (CZ)]. Common chemicals such as sulfuric acid (purum p.a.), potassium dichromate (crystalline p.a.) and hydrogen peroxide (30\% p.a.) were obtained from Penta (CZ). The distilled water was purified in the PureLab Classic system (Veolia, United Kingdom). The non-perfume soap Amadeus Neutral was purchased from Cormen (CZ). Helium 5.5 from Linde (CZ) was used as a carrier gas. All standards (pure, list of standards is presented in Table 1) were obtained from Sigma-Aldrich (USA).

Glass beads (a diameter of $3.6 \mathrm{~mm}$ ) were obtained from Glass Sphere $(\mathrm{CZ})$, cotton gauze squares $(5 \times 5 \mathrm{~cm}, 20$ fibers per $\mathrm{cm}^{2}$ ) from BATIST (CZ), polypropylene non-woven fabric made from Raucodrape ${ }^{\circledR}(5 \times 5 \mathrm{~cm}, 15 \mathrm{gsm})$ from Lohmann \& Rauscher (Austria), nanotextiles (acetate cellulose $20 \mathrm{gsm}$, polyurethane $4.0 \mathrm{gsm}$ and polyvinylidene fluoride $3.2 \mathrm{gsm}$ ) from Nanovia (CZ), the DNA-kit (FLOQSwabs ${ }^{\mathrm{TM}}$ ) from COPAN (Italia) and the Aratex ${ }^{\circledR}$ squares $(40 \times 40 \mathrm{~cm}$, $75 \%$ cotton, $20 \%$ viscose, $5 \%$ polyester, $280 \mathrm{gsm}$ ) from Chlum-tex (CZ).

\section{Model mixture of standards}

A stock solution of 60 standards was prepared by weighing $10 \mathrm{mg}$ of each substance into a $10 \mathrm{~mL}$ volumetric flask and by dissolving them in hexane. This stock solution with a concentration of $1 \mathrm{~g} \mathrm{~L}^{-1}$ was diluted to the working solution with a concentration of $100 \mathrm{mg} \mathrm{L}^{-1}$ which is the so-called "model mixture". This solution was successively diluted to get the six calibration solutions with the concentrations 0.5 ; $1 ; 5 ; 10 ; 25$; and $50 \mathrm{mg} \mathrm{L}^{-1}$.

\section{Cleaning of the sampling material}

In the following paragraphs, only the optimal cleaning methods for the individual sorbents are noted.

\section{Glass beads}

The chromosulfuric mixture was prepared by mixing $0.5 \mathrm{~L}$ of sulfuric acid and $30 \mathrm{~g}$ of potassium dichromate. The glass beads were placed in this mixture for at least $24 \mathrm{~h}$. The excess of the chromosulfuric mixture was decanted over a watch glass back into a stock bottle. The residues of the chromosulfuric mixture were reduced by diluted hydrogen peroxide (5\%). The glass beads were successively washed three times by purified water, ethanol, and hexane and again by ethanol. Then, 70 clean glass beads (it corresponds to a volume of approximately $4 \mathrm{~mL}$ ) were placed into clean beakers and dried in an oven at $200{ }^{\circ} \mathrm{C}$ for $3 \mathrm{~h}$. The dry glass beads were stored in a desiccator before sampling for a maximal period of 7 days.

\section{Textile materials}

Cotton gauze and the Aratex ${ }^{\circledR}$ squares (cut to $5 \times 5 \mathrm{~cm}$ ) were placed into beakers with purified water and they were ultrasonicated for $10 \mathrm{~min}$ in this water bath. Subsequently, the squares were rinsed three times with purified water and then with ethanol, hexane and again with ethanol. The wet squares were dried in an oven at $200{ }^{\circ} \mathrm{C}$ for $3 \mathrm{~h}$ and then stored in a desiccator.

The squares of polypropylene non-woven fabric (PPWNF) from Raucodrape ${ }^{\circledR}$ (cut to $5 \times 5 \mathrm{~cm}$ ) were placed into beakers with ethanol and ultrasonicated for $10 \mathrm{~min}$ in a water bath. This procedure was repeated three times with ethanol and then three times with hexane. The wet squares were dried in the oven at $60^{\circ} \mathrm{C}$ for $1 \mathrm{~h}$ and stored in a desiccator. 
Table 1 List of the compounds presented in model mixture with their retention indices and extraction recoveries from different solvents and using evaporation at reduced pressure

\begin{tabular}{|c|c|c|c|c|c|c|}
\hline & \multirow[t]{2}{*}{ No. } & \multirow[t]{2}{*}{$m / z^{*}$} & \multirow{2}{*}{$\begin{array}{l}\text { Reten- } \\
\text { tion } \\
\text { indices }\end{array}$} & \multicolumn{3}{|c|}{ Extraction recovery $(\%)$} \\
\hline & & & & Hexane & Ethanol & Methanol \\
\hline \multicolumn{7}{|l|}{ Hydrocarbons } \\
\hline Nonane & 1 & 43 & 900 & $19.64(90)$ & $-{ }^{\mathrm{a}}$ & $-{ }^{\mathrm{a}}$ \\
\hline Decane & 3 & 57 & 1000 & $20.64(57)$ & $0.974(65)$ & $--^{\mathrm{a}}$ \\
\hline Undecane & 6 & 57 & 1100 & $45.75(35)$ & $9.46(39)$ & $0.195(88)$ \\
\hline Dodecane & 9 & 57 & 1200 & $64.05(26)$ & $64.50(54)$ & $1.85(20)$ \\
\hline Tridecane & 12 & 57 & 1300 & $72.41(33)$ & $56.17(38)$ & $17.38(71)$ \\
\hline Tetradecane & 15 & 57 & 1400 & $81.09(12)$ & $71.98(97)$ & $49.2(18)$ \\
\hline Pentadecane & 21 & 57 & 1500 & $84.6(16)$ & $95.83(70)$ & $85.40(90)$ \\
\hline Hexadecane & 24 & 57 & 1600 & $94.07(59)$ & $92.11(70)$ & $88.7(33)$ \\
\hline Heptadecane & 27 & 57 & 1700 & $93.2(15)$ & $92.81(92)$ & $88.0(51)$ \\
\hline Octadecane & 29 & 57 & 1800 & $98.74(85)$ & $93.9(15)$ & $92.7(15)$ \\
\hline Nonadecane & 31 & 57 & 1900 & 99.01 (27) & $90.61(20)$ & $93.8(16)$ \\
\hline Eicosane & 33 & 57 & 2000 & $97.1(12)$ & $97.404(88)$ & $93.4(17)$ \\
\hline Heneicosane & 35 & 57 & 2100 & $97.3(11)$ & $94.68(70)$ & $95.9(20)$ \\
\hline Docosane & 37 & 57 & 2200 & 98.27 (70) & $97.55(91)$ & $92.5(28)$ \\
\hline Tricosane & 38 & 57 & 2300 & 99.08 (34) & $95.4(10)$ & $92.0(21)$ \\
\hline Tetracosane & 40 & 57 & 2400 & $98.74(59)$ & $97.41(41)$ & $92.3(21)$ \\
\hline Pentacosane & 41 & 57 & 2500 & $98.62(73)$ & $98.0(27)$ & $91.28(87)$ \\
\hline Hexacosane & 42 & 57 & 2600 & $98.0(18)$ & $98.2(23)$ & $93.52(77)$ \\
\hline Heptacosane & 43 & 57 & 2700 & $97.71(93)$ & $97.9(31)$ & $93.9(15)$ \\
\hline Octacosane & 45 & 57 & 2800 & $98.90(35)$ & 98.48 (77) & $87.8(22)$ \\
\hline Squalene & 46 & 69 & 2817 & $99.6(18)$ & $97.656(47)$ & 97.8 (19) \\
\hline Nonacosane & 47 & 57 & 2900 & $98.5(15)$ & $96.1(19)$ & $92.3(13)$ \\
\hline Triacontane & 49 & 57 & 3000 & $97.5(11)$ & $94.6(31)$ & $86.5(37)$ \\
\hline Hentriacontane & 50 & 57 & 3100 & $98.6(28)$ & $94.6(15)$ & $87.2(84)$ \\
\hline Dotriacontane & 53 & 57 & 3200 & $90.39(80)$ & $94.5(36)$ & $74(11)$ \\
\hline Tritriacontane & 54 & 57 & 3300 & 91.11 (97) & $93.3(23)$ & $64(14)$ \\
\hline Tetratriacontane & 58 & 57 & 3400 & $95.3(24)$ & $89.9(48)$ & $56(14)$ \\
\hline Pentatriacontane & 59 & 57 & 3500 & $99.2(20)$ & $91.3(39)$ & $52(14)$ \\
\hline Hexatriacontane & 60 & 57 & 3600 & $91.7(18)$ & $89.8(17)$ & $46(14)$ \\
\hline Heptatriacontane & 61 & 57 & 3700 & $92.0(17)$ & $89.1(18)$ & $44(13)$ \\
\hline Octatriacontane & 64 & 57 & 3800 & $85.8(20)$ & $83.25(90)$ & $42(14)$ \\
\hline Nonatriacontane & 65 & 57 & 3900 & 84.7 (19) & $80.8(15)$ & $41(14)$ \\
\hline Tetracontane & 66 & 57 & 4000 & $85.6(18)$ & $81.73(47)$ & $40(13)$ \\
\hline \multicolumn{7}{|l|}{ Aldehydes } \\
\hline Decanal & 10 & 82 & 1206 & $51.00(54)$ & $4.01(12)$ & $7.01(46)$ \\
\hline Dodecanal & 16 & 82 & 1409 & $75.2(12)$ & $24.9(24)$ & $21.8(18)$ \\
\hline Tridecanal & 22 & 82 & 1502 & $78.1(96)$ & $39.33(16)$ & $20.7(15)$ \\
\hline Tetradecanal & 25 & 82 & 1615 & $79.9(16)$ & $47.56(46)$ & $22.5(72)$ \\
\hline \multicolumn{7}{|l|}{ Ketones } \\
\hline Octan-2-one & 2 & 58 & 988 & $27.59(44)$ & $29.10(34)$ & $-^{\mathrm{a}}$ \\
\hline Nonan-2-one & 4 & 58 & 1090 & 33.17 (26) & $28.69(23)$ & $2.54(12)$ \\
\hline Decan-2-one & 8 & 58 & 1191 & $57.11(13)$ & $63.7(10)$ & $13.3(11)$ \\
\hline Dodecan-2-one & 14 & 58 & 1394 & $78.81(54)$ & $77.0(13)$ & $69.6(33)$ \\
\hline 6,10-Dimethyl-5,9-undecadien-2-one** & 17 & 43 & 1427 & $70.82(79)$ & $75.8(14)$ & $70.2(36)$ \\
\hline 6,10-Dimethyl-5,9-undecadien-2-one** & 18 & 43 & 1445 & $72.66(74)$ & $75.8(12)$ & $73.5(40)$ \\
\hline Tridecan-2-one & 20 & 58 & 1495 & $81.98(61)$ & $84.3(13)$ & $84.4(33)$ \\
\hline Pentadecan-2-one & 26 & 58 & 1698 & $92.7(13)$ & $93.2(25)$ & $90.6(36)$ \\
\hline Octadecan-2-one & 34 & 58 & 2003 & $99.41(19)$ & $94.32(82)$ & $93.4(12)$ \\
\hline
\end{tabular}


Table 1 (continued)

\begin{tabular}{|c|c|c|c|c|c|c|}
\hline & \multirow[t]{2}{*}{ No. } & \multirow[t]{2}{*}{$m / z^{*}$} & \multirow{2}{*}{$\begin{array}{l}\text { Reten- } \\
\text { tion } \\
\text { indices }\end{array}$} & \multicolumn{3}{|c|}{ Extraction recovery $(\%)$} \\
\hline & & & & Hexane & Ethanol & Methanol \\
\hline \multicolumn{7}{|l|}{ Esters } \\
\hline Butyl ester of pentanoic acid & 5 & 85 & 1093 & $46.45(23)$ & $40.01(51)$ & $0.37(10)$ \\
\hline Butyl ester of hexanoic acid & 7 & 56 & 1190 & $58.35(17)$ & $57.14(64)$ & $7.51(67)$ \\
\hline Butyl ester of heptanoic acid & 11 & 56 & 1288 & $66.4(11)$ & $70.0(11)$ & $31.0(24)$ \\
\hline Butyl ester of octanoic acid & 13 & 56 & 1387 & $73.01(11)$ & $77.1(13)$ & $61.0(27)$ \\
\hline Butyl ester of nonanoic acid & 19 & 56 & 1484 & $75.16(90)$ & $77.5(12)$ & $76.7(34)$ \\
\hline Butyl ester of decanoic acid & 23 & 56 & 1582 & $89.30(46)$ & $85.0(14)$ & $89.2(38)$ \\
\hline Butyl ester of dodecanoic acid & 28 & 56 & 1786 & $98.79(97)$ & $88.2(18)$ & $95.6(34)$ \\
\hline Isopropyl myristate & 30 & 43 & 1824 & $97.3(11)$ & $86.5(19)$ & $84(13)$ \\
\hline Butyl ester of tetradecanoic acid & 32 & 56 & 1984 & $97.67(72)$ & $93.93(14)$ & $96.9(18)$ \\
\hline Butyl ester hexadecanoic acid & 36 & 56 & 2182 & $98.6(17)$ & $98.6(31)$ & $95.8(20)$ \\
\hline Butyl ester of octadecanoic acid & 39 & 56 & 2386 & $94.5(14)$ & $97.7(36)$ & $97.49(92)$ \\
\hline Dodecyl ester of tetradecanoic acid & 44 & 57 & 2765 & $97.1(27)$ & $93.70(84)$ & $95.5(13)$ \\
\hline Dodecyl ester of hexadec-9-enoic acid & 48 & 57 & 2953 & $99.84(99)$ & $95.2(12)$ & $91.1(19)$ \\
\hline Dodecyl ester of octadec-9-enoic acid & 51 & 57 & 3148 & $96.8(17)$ & $96.7(26)$ & $95.90(77)$ \\
\hline Dodecyl ester of octadecanoic acid & 52 & 57 & 3165 & $99.8(15)$ & $93.7(29)$ & $96.30(27)$ \\
\hline Hexadecyl ester of hexadecanoic acid & 55 & 257 & 3365 & $92.4(38)$ & $99.75(10)$ & $95.85(59)$ \\
\hline Eicosyl ester of dodecanoic acid & 56 & 201 & 3365 & $91.0(33)$ & $99.04(33)$ & $94.36(74)$ \\
\hline Dodecyl ester of eicosanoic acid & 57 & 313 & 3365 & $98.3(20)$ & $99.71(39)$ & $93.27(59)$ \\
\hline Octadec-9-enyl ester of octadec-9-enoic acid & 62 & 57 & 3723 & $99.3(35)$ & $94.62(62)$ & $89.4(17)$ \\
\hline Octadecyl ester of octadecanoic acid & 63 & 285 & 3766 & $99.4(14)$ & $99.99(27)$ & $83.5(40)$ \\
\hline
\end{tabular}

Values in parentheses are standard deviations of the means of the extraction recoveries. They are expressed in units of their last two decimal digits

*The dimensionless quantity $\mathrm{m} / \mathrm{z}$, means mass-to-charge ratio used for quantification

${ }^{* *}$ Stereoisomers

${ }^{\mathrm{a}}$ Compound concentration was under LOD

\section{Nanotextiles}

The squares of acetate cellulose $(\mathrm{ACC}, 5 \times 5 \mathrm{~cm})$ were placed into beakers with ethanol and ultrasonicated for $20 \mathrm{~min}$ in a water bath. This procedure was repeated three times. The squares of polyurethane (PUR) and polyvinylidene fluoride (PVDF, $5 \times 5 \mathrm{~cm}$ ) were placed into beakers with hexane and ultrasonicated for $20 \mathrm{~min}$ in a water bath. This procedure was repeated three times. The wet squares were dried in the oven at $60{ }^{\circ} \mathrm{C}$ for $1 \mathrm{~h}$ and stored in a desiccator.

\section{DNA kit}

The applicator from the DNA kit was cleaned using water and organic solvents. First, the applicator was ultrasonicated in purified water for $10 \mathrm{~min}$, then in ethanol and then in hexane for $10 \mathrm{~min}$. The wet applicator was dried at $150{ }^{\circ} \mathrm{C}$ for $1 \mathrm{~h}$.

\section{Sample handling}

\section{Extraction from the glass beads}

A volume of $100 \mu \mathrm{L}$ of the standard mixture (concentration $50 \mathrm{mg} \mathrm{L}^{-1}$ ) was applied to the 70 clean glass beads in a $20 \mathrm{~mL}$ headspace vial (except for the blank samples). A volume of $1 \mathrm{~mL}$ of solvents (hexane, ethanol, methanol, acetonitrile) was used for the extraction of the "model mixture" compounds (see Table 1) from the glass beads. The extraction was carried out in a shaker for $10 \mathrm{~min}$ and then put into the ultrasonic bath for $10 \mathrm{~min}$. The solvent extracts were successively transferred into $1 \mathrm{~mL}$ vials and evaporated to dryness using different procedures; either evaporation at laboratory temperature and atmospheric pressure, or evaporation at $60{ }^{\circ} \mathrm{C}$ and at atmospheric pressure or, finally, evaporation at laboratory temperature and under reduced pressure of 100 mbar in a Genevac EZ-2 evaporating system. The extraction procedure was repeated with a further $1 \mathrm{~mL}$ of the solvents and these parts were transferred to the first 
vaporized parts in the vials and evaporated to dryness again. The dry residues were dissolved in the $100 \mu \mathrm{L}$ corresponding solvents and analyzed by GC-MS.

\section{Real samples}

The volunteers [5 men (M1-M5) and 5 women (F1-F5) aged 24-28 years old, Europoid race, non-smokers, healthy, no regular medications except contraception in F1, F4, and F5 cases] were asked not to use any cosmetic products (perfumes, antiperspirants, creams, make-up, etc.) at least $24 \mathrm{~h}$ before sample collections in order to reduce undesirable contaminations. Samples of the human scent were collected from their palms. The volunteers washed their hands with a non-perfumed soap for $30 \mathrm{~s}$ and then the soap was rinsed off under warm tap water. The palms were left to dry in the air and after that by rubbing the palms together the palm glands were left for $5 \mathrm{~min}$ to activate and produce the clean human scent. The proper skin scent was collected from the palms to the clean glass beads by squeezing and rubbing in the dried palms together for $10 \mathrm{~min}$. Each volunteer provided two samples in this way.

The extraction was carried out by $1 \mathrm{~mL}$ into hexane. The obtained solutions were placed into a shaker for $10 \mathrm{~min}$ and then put into the ultrasonic bath for $10 \mathrm{~min}$. The scent extracts were successively transferred into $1 \mathrm{~mL}$ vials and evaporated to dryness at the reduced pressure of $100 \mathrm{mbar}$. The extraction procedure was repeated with a further $1 \mathrm{~mL}$ of hexane and the second parts of the extract were transferred to the first vaporized parts in the vials and evaporated to dryness again. The dry residues were dissolved in $50 \mu \mathrm{L}$ of hexane and analyzed by GC-MS. An analogous procedure was applied to the second samples taken, which were instead extracted into ethanol.

\section{Instrumentation}

The measurements were carried out on a GC-MS TQ 8030 (Shimadzu) device equipped with a nonpolar column SLB-5 ms $(30 \mathrm{~m} \times 0.25 \mathrm{~mm} \times 0.25 \mu \mathrm{m}$, Supelco $)$. The optimized measurement method for the separation of compounds was the following: $50{ }^{\circ} \mathrm{C}-2 \mathrm{~min}-5{ }^{\circ} \mathrm{C} /$ $\min -150{ }^{\circ} \mathrm{C}-5 \min -8{ }^{\circ} \mathrm{C} / \min -220{ }^{\circ} \mathrm{C}-5 \min -8{ }^{\circ} \mathrm{C} /$ $\min -320{ }^{\circ} \mathrm{C}-16.75 \mathrm{~min}$; the total time of the analysis was $70 \mathrm{~min}$. A high pressure (200 $\mathrm{kPa}, 2 \mathrm{~min})$ injection was used to apply $1 \mu \mathrm{L}$ of the sample in a splitless mode. An injection port was set at $280^{\circ} \mathrm{C}$. Helium was used as the carrier gas at a constant pressure of $100 \mathrm{kPa}$. The transfer line was tempered at $280{ }^{\circ} \mathrm{C}$ and the ion source at $220^{\circ} \mathrm{C}$. The ionization energy was set to $70 \mathrm{eV}$ and the range of $\mathrm{m} / \mathrm{z}$ was $25-600$.

The obtained data were analyzed in the GC-MS Postrun Analysis program. Compounds corresponding to the individual peaks were identified according to the retention indexes, based on knowledge of the mass spectra and using the NIST MS Search 2.0 program (Stein 2011). The retention index calculation was based on linear retention indices (LRIs) (Vandendool and Kratz 1963). The retention index standard uncertainties were estimated to one.

\section{Results and discussion}

\section{Optimization of separation conditions}

In the first step, the separation conditions were optimized on the basis of the achieved chromatographic resolution. At the beginning, a linear gradient of temperature was applied from 50 to $300{ }^{\circ} \mathrm{C}$ with the rate of $8{ }^{\circ} \mathrm{C} / \mathrm{min}$. Using this program, compounds eluted in the 9th min (butyl ester of pentanoic acid with decan-2-one, butyl ester of pentanoic acid with undecane), in the 17th min (pentadecane with tridecan2-one) and in the 24th min (eicosane with octadecan-2-one) were co-eluted. Also, not all hydrocarbons were eluted from the chromatographic column; the last eluted compound was tetratriacontane. To improve the separation, two isothermal plates (at $150{ }^{\circ} \mathrm{C}$ and $220{ }^{\circ} \mathrm{C}$ ) were added and the rate of the gradient in the first part (to $150{ }^{\circ} \mathrm{C}$ ) was decreased to $5{ }^{\circ} \mathrm{C} / \mathrm{min}$. In addition, the final temperature was increased to $320{ }^{\circ} \mathrm{C}$ to elute all the $n$-alkanes to tetracontane. The total ion current chromatogram of the optimized separation is shown in Fig. 1. The unresolved chromatographic peaks were separated using the deconvolution using their specific ion masses (see Table 1).

The stock solution with a concentration of $1 \mathrm{~g} \mathrm{~L}^{-1}$ was diluted into 6 calibration solutions at concentrations from 0.5 to $50 \mathrm{mg} \mathrm{L}^{-1}$. All the solutions and blank samples (pure hexane) were measured three times under optimized conditions. The quant masses were chosen for each compound (Table 1) and its area was integrated and used to create the calibration curves. The limits of detection and quantification were calculated as treble and tenfold of the signal to noise value, respectively.

\section{Selection of the sorbent materials}

Sampling is probably the most critical part of sample preparation. We tested different materials as sorbents, namely glass beads, different textile fabrics, cotton gauze, medical compresses from non-woven fabric or a DNA kit, for the sample collection.

Aratex ${ }^{\circledR}$ is a textile fabric consisting of cotton, viscose and polyester. According to the Czech Police regulations, Aratex ${ }^{\circledR}$ is used as a sorbent for scent sample collection for individual identifications of persons by specially trained dogs (Schoon and Haak 2002). However, our experiments imply that this fabric is not sufficiently cleanable and, 
Fig. 1 Total ion current (TIC) chromatogram and chromatogram at the selected mass of the compounds presented in the model mixture $\left(c=50 \mathrm{mg} \mathrm{L}^{-1}\right)$ obtained under optimized conditions. Their retention indices and quant masses are listed in Table 1

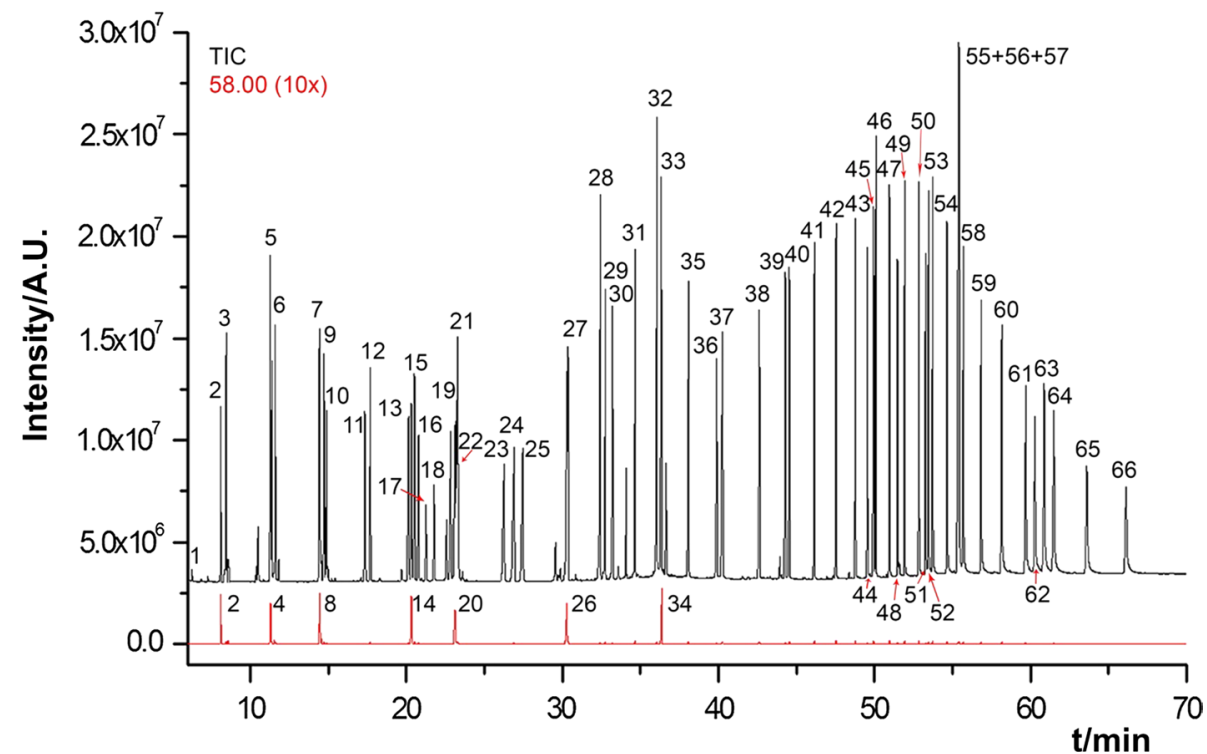

therefore, it is unsuitable for instrumental analyses, as shown in Fig. 2. Aratex ${ }^{\circledR}$ contains many impurities and most of them cannot be sufficiently washed out using solvents such as water, hexane and ethanol. Similar results were observed for the sterile cotton gauze used in hospitals (Fig. 2). The nanotextile fabrics could be cleaned better, but contamination was still high (Fig. 3). The most abundant impurities were bis(2-ethylhexyl) hexanedioate, 2-hydroxy-1-(hydroxymethyl)ethyl hexadecanoate, 2-hydroxy-1-(hydroxymethyl) ethyl octadecanoate, and 13-docosenamide). Polypropylene non-woven fabric was the only textile material that had a small amount of impurities after cleaning (Fig. 3). Another tested material, commonly used by the police, was the DNA kit. The problem with this sorbent is the presence of preservatives for the safe storage of biological samples. These compounds are also hard to wash out (Fig. 2). Due to the high amount of the various impurities, these materials were not used for other experiments with the model mixture solution.

The most suitable tested sorbent was glass beads. The great advantage of glass beads is their chemical resistance, which allows the most profound cleaning, e.g., in a chromosulfuric mixture, in different solvents, etc. They are also thermally stable and chemically inert. Figure 2 shows the chromatogram of the hexane extract of the cleaned glass beads. Some impurities are visible between the 40th and 50 th min, but these come from the organic solvent. Therefore, this glass sorbent was selected as the most suitable for the collection of the human scent samples.

\section{Selection of the extraction solvents}

Four different solvents with various polarities (hexane, ethanol, methanol and acetonitrile) were tested as the solvents
Fig. 2 TIC chromatograms of the concentrated extracts from the various "cleaned" sorbents into hexane, the cleaning procedure is described in "Cleaning of the sampling material" and extraction and pre-concentration in "Sample handling". The measurements were done under optimized conditions (see "Instrumentation"). Note the different intensity scales of the upper and lower chromatograms

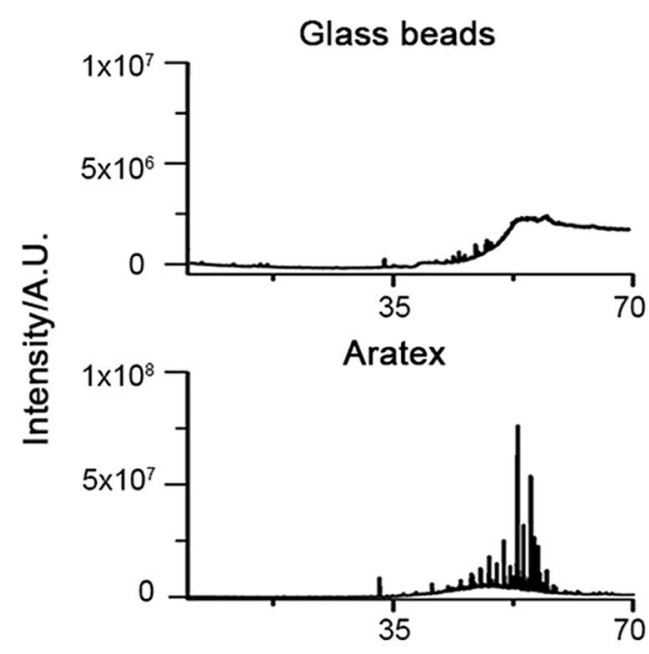


Fig. 3 TIC chromatograms of the concentrated extracts from the various cleaned sorbents into hexane, the cleaning procedure is described in "Cleaning of the sampling material" and extraction and pre-concentration in "Sample handling". The measurements were done under optimized conditions (see "Instrumentation")

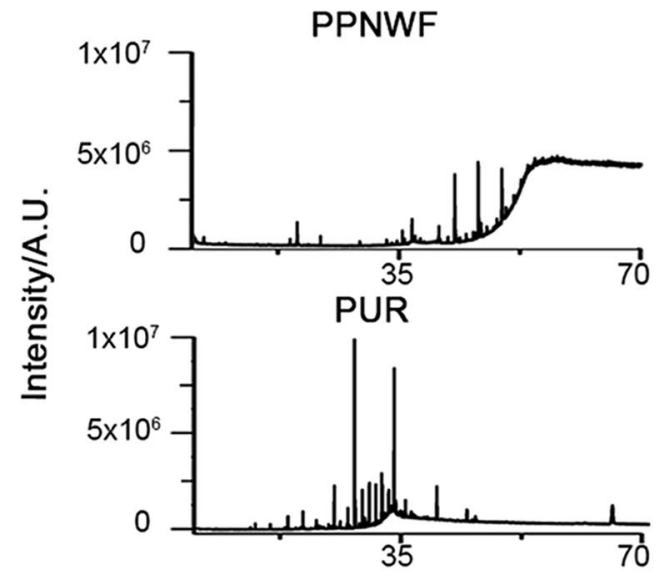

for scent compound extraction from the sorbents. Their extraction affinities to all compounds present in the model mixture were compared in terms of their extraction recoveries and their impurities.

In blank samples (pure solvents) which were evaporated to dryness using free evaporation at laboratory temperature, the least amount of impurities occurs in hexane; however, the lowest concentration of impurities was achieved by extraction into acetonitrile.

In the model samples, the best results were achieved in the hexane and ethanol solutions. The results for the acetonitrile solutions were nonhomogeneous and the extraction recoveries were heavily interpretable. Because of these results and its strong toxicity, acetonitrile was excluded as the solvent from the other experiments.

\section{Optimization of solvent evaporation}

The evaporation of the solvents described in "Selection of the extraction solvents" was performed by evaporation at laboratory temperature and atmospheric pressure conditions. The main disadvantage of this procedure was its hardly acceptable evaporation time: hexane-1.5 days, ethanol-5 days, methanol-3 days, acetonitrile -3 days.

In an attempt to reduce the evaporation time, the evaporation temperature was increased to $60{ }^{\circ} \mathrm{C}$. This alteration shortened the evaporation times by about $30 \%$. Also, the amount of impurities in the blank extracts was decreased.

Next, evaporation at laboratory temperature and reduced pressure (approx. 100 mbar) was tested. Using reduced pressure, the evaporation time decreased by an additional $85-95 \%$, specifically hexane-3 $\mathrm{h}$, ethanol $-4 \mathrm{~h}$, methanol-4 h. This procedure also allowed the preparation of the samples with the lowest occurrence of impurities.

All the compounds' recoveries obtained at the reduced pressure are listed in Table 1.

\section{Real scent sample analyses}

On the basis of our studies with the model mixture (see Fig. 1) containing "scent-like" compounds, the hexane and ethanol solvents were selected for analyses with the real scent samples. These solvents enable the best extraction recoveries with the smallest statistical variance. In addition to this, these solvents are significantly less harmful than methanol and acetonitrile.

The scent samples collected from ten volunteers ( 5 males and 5 females) were extracted into hexane as well as into ethanol. Using GC-MS (see "Instrumentation"), more than 500 compounds in total have been observed in these 20 samples. In all, 218 different chemical compounds were unambiguously identified, specifically 175 in hexane and 172 in ethanol extracts.

In the real scent samples, all the alkanes from the model mixture (see Table 1; Fig. 1) were identified except octatriacontane, nonatriacontane and tetracontane. All the aldehydes from the model mixture were present. Of the ketones, only decan-2-one and 6,10-dimethyl-5,9-undecadien-2-one (just one from two isomers) were observed and, finally, of the esters, those found were only isopropyl myristate, the butyl ester of octadecanoic acid and the hexadecyl ester of hexadecanoic acid.

Of all the compounds observed in the real scent samples, the compounds present in the scent samples of the majority of the volunteers (no less than in nine of the ten samples in the given solvent) were searched with the aim to delimit the molecules of the primary scent. In all, 28 and 42 such compounds were found in the hexane and the ethanol solutions, respectively. These compounds are listed in Tables 2 and 3. Figure 4 represents an example of a real scent sample chromatogram. 
Table 2 List of the compounds identified in real samples extracted into hexane that occurred in at least 9 of the 10 cases

\begin{tabular}{|c|c|c|c|c|c|c|c|c|c|c|c|}
\hline & $\begin{array}{l}\text { Reten- } \\
\text { tion } \\
\text { indices }\end{array}$ & M1 & M2 & M3 & M4 & M5 & F1 & $\mathrm{F} 2$ & F3 & F4 & F5 \\
\hline \multicolumn{12}{|l|}{ Hydrocarbons } \\
\hline Tricosane & 2300 & $\times$ & $x$ & $\times$ & $x$ & $\times$ & $x$ & $x$ & $\times$ & $x$ & \\
\hline Tetracosane & 2400 & $\times$ & $x$ & $\times$ & $x$ & $x$ & $x$ & $x$ & $x$ & $x$ & $x$ \\
\hline Hexacosane & 2600 & $x$ & $x$ & $x$ & $x$ & $\times$ & $x$ & & $x$ & $x$ & $x$ \\
\hline Squalene & 2817 & $\times$ & $x$ & $\times$ & $x$ & $x$ & $x$ & $x$ & $x$ & $x$ & $x$ \\
\hline Nonacosane & 2900 & $\times$ & $x$ & $\times$ & $x$ & $x$ & $x$ & $x$ & & $x$ & $x$ \\
\hline \multicolumn{12}{|l|}{ Aldehydes } \\
\hline Nonanal & 1105 & $x$ & $\times$ & $\times$ & $x$ & $x$ & $x$ & $x$ & $x$ & $x$ & $x$ \\
\hline Decanal & 1207 & $\times$ & $\times$ & $\times$ & $\times$ & $\times$ & $\times$ & $x$ & $\times$ & $x$ & $x$ \\
\hline \multicolumn{12}{|l|}{ Ketones } \\
\hline 6,10-Dimethyl-5,9-undecadien-2-one & 1445 & $\times$ & $\times$ & $\times$ & $x$ & $\times$ & $x$ & $\times$ & $\times$ & $x$ & $x$ \\
\hline \multicolumn{12}{|l|}{ Alcohols } \\
\hline Dodecan-1-ol & 1478 & $\times$ & $\times$ & $\times$ & $\times$ & $\times$ & $x$ & $\times$ & $\times$ & $x$ & $x$ \\
\hline Tetradecan-1-ol & 1679 & $\times$ & $x$ & & $x$ & $\times$ & $x$ & $\times$ & $\times$ & $x$ & $x$ \\
\hline \multicolumn{12}{|l|}{ Ethers } \\
\hline 2-(Dodecyloxy)-ethanol & 1718 & $\times$ & $x$ & $\times$ & $\times$ & $\times$ & $x$ & $x$ & $\times$ & $x$ & $x$ \\
\hline Diethylen glycol monodecyl ether & 1991 & $\times$ & $\times$ & $\times$ & $x$ & $\times$ & & $x$ & $\times$ & $x$ & $x$ \\
\hline \multicolumn{12}{|l|}{ Acids } \\
\hline Decanoic acid & 1361 & $\times$ & $x$ & & $x$ & $\times$ & $x$ & $\times$ & $\times$ & $x$ & $x$ \\
\hline Dodecanoic acid & 1561 & $x$ & $x$ & $\times$ & $x$ & $x$ & $\times$ & $x$ & $x$ & $x$ & $x$ \\
\hline Tetradecanoic acid & 1760 & $\times$ & $x$ & $\times$ & $x$ & $x$ & $\times$ & $x$ & $\times$ & $x$ & $x$ \\
\hline Pentadecanoic acid & 1856 & $x$ & $x$ & $x$ & $x$ & $x$ & $x$ & $x$ & $x$ & $x$ & $x$ \\
\hline Hexadec-9-enoic acid & 1932 & $\times$ & $\times$ & $\times$ & $\times$ & $\times$ & $\times$ & & $\times$ & $x$ & $x$ \\
\hline Hexadecanoic acid & 1956 & $\times$ & $x$ & $\times$ & $x$ & $x$ & $\times$ & $x$ & $\times$ & $x$ & $x$ \\
\hline Heptadecanoic acid & 2059 & $\times$ & $x$ & $\times$ & $\times$ & $\times$ & $\times$ & & $\times$ & $x$ & $x$ \\
\hline Octadec-9-enoic acid & 2138 & $\times$ & $x$ & $\times$ & $\times$ & $\times$ & $\times$ & & $\times$ & $x$ & $x$ \\
\hline Octadecanoic acid & 2162 & $\times$ & $\times$ & $\times$ & $\times$ & $x$ & $\times$ & $x$ & $\times$ & $x$ & $x$ \\
\hline \multicolumn{12}{|l|}{ Esters } \\
\hline Tetradecyl ester of hexadec-9-enoic acid & 3144 & $\times$ & $\times$ & $\times$ & $\times$ & $\times$ & $x$ & $\times$ & & $x$ & $x$ \\
\hline Hexadecyl ester of hexadec-9-enoic acid & 3344 & $\times$ & $x$ & $x$ & $x$ & $\times$ & $\times$ & $x$ & & $x$ & $x$ \\
\hline Hexadecyl ester of hexadecanoic acid & 3365 & $\times$ & $\times$ & $\times$ & $\times$ & $\times$ & $\times$ & $\times$ & & $x$ & $x$ \\
\hline Octadecyl ester of hexadec-9-enoic acid & 3543 & $x$ & $x$ & $x$ & $x$ & $x$ & $x$ & $x$ & $\times$ & $x$ & $x$ \\
\hline Octadecyl ester of hexadecanoic acid & 3564 & $\times$ & $\times$ & $\times$ & $\times$ & $\times$ & $\times$ & $x$ & & $x$ & $x$ \\
\hline \multicolumn{12}{|l|}{ Others } \\
\hline 1-Methyl-2-pyrrolidinone & 1041 & $\times$ & $\times$ & $\times$ & $\times$ & $\times$ & $\times$ & $x$ & $x$ & $x$ & $x$ \\
\hline Cholesterol & 3159 & $\times$ & $x$ & $\times$ & $x$ & $\times$ & $x$ & $\times$ & $\times$ & $\times$ & $x$ \\
\hline
\end{tabular}

The symbols " $X$ " denote compounds that were present in the sample

\section{Conclusions}

The optimal procedure to obtain the human skin scent samples was developed and described. In addition, the most appropriate separation conditions for the GC-MS chemical analyses were found and presented.

Glass beads were selected as the best sorbent for the human scent collection, since the possibility of its faultless purification allowed a minimalization of the undesirable contaminations of the scent samples. Glass is an inert, chemically and thermally stable material which is easy to perfectly clean out. Furthermore, manipulation with this sorbent is not extremely difficult. Even though glass has worse sorption properties than, e.g., gauze or non-woven fabrics, the higher-order cleanness of the glass sorbent provided the best results in our scent chemical analyses. The reason for this decision lies in the fact that the relative concentrations of the plentiful scent compounds are comparable or even smaller than the contaminations of these sorbents.

The polypropylene non-woven fabric was also found to be useable for chemical scent analyses. The impurity background is only about half an order of magnitude higher, but 
Table 3 List of the compounds identified in real samples extracted into ethanol that occurred in at least 9 of the 10 cases

\begin{tabular}{|c|c|c|c|c|c|c|c|c|c|c|c|}
\hline & $\begin{array}{l}\text { Retention } \\
\text { indices }\end{array}$ & M1 & M2 & M3 & M4 & M5 & $\mathrm{F} 1$ & $\mathrm{~F} 2$ & $\mathrm{~F} 3$ & F4 & F5 \\
\hline \multicolumn{12}{|l|}{ Hydrocarbons } \\
\hline Squalene & 2817 & $\times$ & $\times$ & $\times$ & $\times$ & $x$ & $x$ & $x$ & $\times$ & $\times$ & $\times$ \\
\hline \multicolumn{12}{|l|}{ Alcohols } \\
\hline Dodecan-1-ol & 1477 & $\times$ & $\times$ & $\times$ & $\times$ & $\times$ & $x$ & $x$ & $\times$ & $x$ & $\times$ \\
\hline 2-Hexyl-decan-1-ol & 1742 & $\times$ & $\times$ & $\times$ & $\times$ & $\times$ & $\times$ & $\times$ & $\times$ & $x$ & \\
\hline \multicolumn{12}{|l|}{ Ethers } \\
\hline 2-(Dodecyloxy)-ethanol & 1718 & $\times$ & $\times$ & $\times$ & $x$ & $\times$ & $x$ & $x$ & $\times$ & $\times$ & \\
\hline Diethylen glycol monodecyl ether & 1991 & $\times$ & $\times$ & $\times$ & $\times$ & $\times$ & $\times$ & $x$ & $\times$ & $\times$ & \\
\hline \multicolumn{12}{|l|}{ Acids } \\
\hline Nonanoic acid & 1264 & $x$ & $x$ & $x$ & $\times$ & $\times$ & $\times$ & $\times$ & $\times$ & $\times$ & $x$ \\
\hline Dodecanoic acid & 1561 & $x$ & $x$ & $x$ & $x$ & $x$ & $x$ & $\times$ & $\times$ & $x$ & \\
\hline L-Glutamic acid & 1660 & $\times$ & $\times$ & $\times$ & $\times$ & $\times$ & $\times$ & $x$ & & $\times$ & $\times$ \\
\hline Tetradecanoic acid & 1759 & $\times$ & $\times$ & $\times$ & $\times$ & $\times$ & $\times$ & $\times$ & $\times$ & $\times$ & $\times$ \\
\hline Pentadecanoic acid & 1856 & $\times$ & $\times$ & $\times$ & $\times$ & $\times$ & $x$ & $x$ & $\times$ & $x$ & $x$ \\
\hline Hexadec-9-enoic acid & 1932 & $\times$ & $\times$ & $\times$ & $\times$ & $\times$ & $\times$ & $\times$ & $\times$ & $x$ & $\times$ \\
\hline Hexadecanoic acid & 1956 & $\times$ & $\times$ & $\times$ & $\times$ & $\times$ & $\times$ & $\times$ & $\times$ & $x$ & $\times$ \\
\hline Heptadecanoic acid & 2059 & $\times$ & $\times$ & $\times$ & $x$ & $x$ & $\times$ & & $x$ & $\times$ & $x$ \\
\hline Octadec-9-enoic acid & 2138 & $\times$ & $\times$ & $\times$ & $\times$ & $\times$ & $\times$ & & $\times$ & $x$ & $x$ \\
\hline Octadecanoic acid & 2162 & $\times$ & $\times$ & $\times$ & $x$ & $\times$ & $\times$ & $x$ & $\times$ & $\times$ & $\times$ \\
\hline \multicolumn{12}{|l|}{ Esters } \\
\hline Dodecyl ester of methoxyacetic acid & 1810 & $\times$ & $\times$ & $x$ & $x$ & $\times$ & $\times$ & $\times$ & $\times$ & $\times$ & $\times$ \\
\hline Tetradecyl ester of methoxyacetic acid & 2014 & & $\times$ & $\times$ & $\times$ & $\times$ & $\times$ & $\times$ & $\times$ & $\times$ & $\times$ \\
\hline Fumaric acid, 2-dimethylaminoethyl heptyl ester & 2228 & $\times$ & $\times$ & $\times$ & $\times$ & $\times$ & $\times$ & $\times$ & $\times$ & $\times$ & $\times$ \\
\hline Fumaric acid, 2-dimethylaminoethyl nonyl ester & 2436 & $x$ & $\times$ & $\times$ & $x$ & $\times$ & $\times$ & $\times$ & $\times$ & $\times$ & $\times$ \\
\hline Fumaric acid, 2-dimethylaminoethyl undecyl ester & 2645 & $\times$ & $\times$ & $\times$ & $\times$ & $\times$ & $\times$ & $\times$ & $\times$ & $x$ & $\times$ \\
\hline Fumaric acid, 2-dimethylaminoethyl tridecyl ester & 2852 & $\times$ & $\times$ & $\times$ & $\times$ & $\times$ & $\times$ & $\times$ & $\times$ & $x$ & $\times$ \\
\hline Dodecyl ester of hexadecanoic acid & 2967 & $\times$ & $\times$ & $\times$ & $\times$ & $\times$ & $\times$ & $\times$ & & $\times$ & $\times$ \\
\hline Tetradecyl ester of hexadec-9-enoic acid & 3144 & $\times$ & $\times$ & $\times$ & $\times$ & $\times$ & $\times$ & $\times$ & & $\times$ & $\times$ \\
\hline Tetradecyl ester of hexadecanoic acid & 3166 & $\times$ & $\times$ & $\times$ & $\times$ & $\times$ & $\times$ & $\times$ & & $\times$ & $x$ \\
\hline Hexadecyl ester of hexadec-9-enoic acid & 3344 & $x$ & $\times$ & $x$ & $\times$ & $\times$ & $\times$ & $\times$ & & $x$ & $x$ \\
\hline Hexadecyl ester of hexadecanoic acid & 3365 & $\times$ & $\times$ & $\times$ & $\times$ & $\times$ & $\times$ & $\times$ & & $\times$ & $\times$ \\
\hline Octadecyl ester of hexadec-9-enoic acid & 3543 & $\times$ & $\times$ & $\times$ & $\times$ & $\times$ & $\times$ & $\times$ & & $\times$ & $\times$ \\
\hline Octadecyl ester of hexadecanoic acid & 3564 & $\times$ & $\times$ & $\times$ & $\times$ & $\times$ & $\times$ & $\times$ & & $\times$ & $\times$ \\
\hline Eicos-9-enyl ester of hexadec-9-enoic acid & 3743 & $\times$ & $\times$ & $\times$ & $\times$ & $\times$ & $\times$ & $\times$ & & $\times$ & $\times$ \\
\hline Eicosyl ester of hexadec-9-enoic acid & 3763 & $\times$ & $\times$ & $\times$ & $\times$ & $\times$ & $x$ & $\times$ & & $\times$ & $x$ \\
\hline \multicolumn{12}{|l|}{ Amides } \\
\hline$N$-allyl-dodecanamide & 1834 & $\times$ & $\times$ & $\times$ & $\times$ & $\times$ & $\times$ & $\times$ & $\times$ & $x$ & $x$ \\
\hline $\mathrm{N}$-allyl-tetradecanamide & 2045 & $\times$ & $\times$ & $\times$ & $\times$ & $\times$ & $\times$ & $\times$ & $\times$ & $\times$ & $x$ \\
\hline Octadecanamide & 2181 & $\times$ & $\times$ & $\times$ & $\times$ & $\times$ & $\times$ & $x$ & $\times$ & $\times$ & $\times$ \\
\hline $\mathrm{N}$-allyl-hexadecanamide & 2253 & $\times$ & $\times$ & $\times$ & $\times$ & $\times$ & $\times$ & $\times$ & $\times$ & $x$ & $\times$ \\
\hline $\mathrm{N}$-allyl-octadecanamide & 2461 & $\times$ & $\times$ & $x$ & $\times$ & $\times$ & $\times$ & $x$ & $\times$ & $\times$ & $x$ \\
\hline \multicolumn{12}{|l|}{ Others } \\
\hline 4-Hydroxydihydrofuran-2-one & 1157 & $x$ & $\times$ & $x$ & $\times$ & $\times$ & $\times$ & $x$ & & $x$ & $\times$ \\
\hline 1-Chlordodecane & 1475 & $\times$ & $\times$ & $\times$ & $\times$ & $\times$ & $\times$ & $\times$ & $\times$ & $x$ & $x$ \\
\hline DL-alanyl-L-leucine & 1735 & $\times$ & $\times$ & $\times$ & $\times$ & $x$ & $x$ & $x$ & $\times$ & $x$ & $x$ \\
\hline $\begin{array}{l}\text { 5,10-Diethoxy-2,3,7,8-tetrahydro-1H,6H- } \\
\text { dipyrrolo[1,2-a:1',2'-d]pyrazine }\end{array}$ & 1948 & $\times$ & $\times$ & $\times$ & $\times$ & $\times$ & $\times$ & $\times$ & $\times$ & $x$ & $\times$ \\
\hline 2-Heptadecyl-5-methylpyrrolidine & 2474 & $\times$ & $\times$ & $\times$ & $\times$ & $x$ & $\times$ & $x$ & $\times$ & $x$ & $\times$ \\
\hline 2-Nonadecyl-5-methylpyrrolidine & 2686 & $\times$ & $\times$ & $x$ & $\times$ & $\times$ & $x$ & $x$ & $\times$ & $x$ & $\times$ \\
\hline
\end{tabular}


Table 3 (continued)

\begin{tabular}{llllllllllllll}
\hline & $\begin{array}{l}\text { Retention } \\
\text { indices }\end{array}$ & M1 & M2 & M3 & M4 & M5 & F1 & F2 & F3 & F4 & F5 \\
\hline Cholesterol & 3159 & $\times$ & $\times$ & $\times$ & $\times$ & $\times$ & $\times$ & $\times$ & $\times$ & $\times$ & $\times$ \\
\hline
\end{tabular}

The symbols " $x$ " denote compounds that were present in the sample

the textile form of the sorbent has certain advantages for possible non-contact sampling methods. The tested nanotextile fabrics are also useable for the scent compound analyses, in principle, but only for the low volatile scent components.

The four different solvents with various polarities (hexane, ethanol, methanol and acetonitrile) tested in this study were rated according to the dissolubility of all the scent compounds; namely as polar, nonpolar, volatile, and little volatile scent compounds.

Ethanol and hexane were evaluated as the most suitable solvents. As shown in Table 1, hexane dilutes nonpolar compounds perfectly, but it dissolves polar ones poorly. On the other hand, the polar compounds are well soluble in ethanol and methanol.

Concerning the pre-concentration procedures, evaporation at reduced pressure was evaluated as the optimal technique for sample concentration. This procedure was unambiguously the fastest with the smallest losses.

The optimized conditions of the sample preparation described above were applied to real human scent samples. In these real samples, more than 200 scent compounds were identified including hydrocarbons, aldehydes, ketones, alcohols, ethers, nitrogenous compounds, fatty acids and their esters. Special attention was paid to the compounds that can be considered to be among the primary molecules, and which can play an important role in the individual human scent identification. These compounds were rather found in the ethanol solutions than in the hexane ones. Therefore,

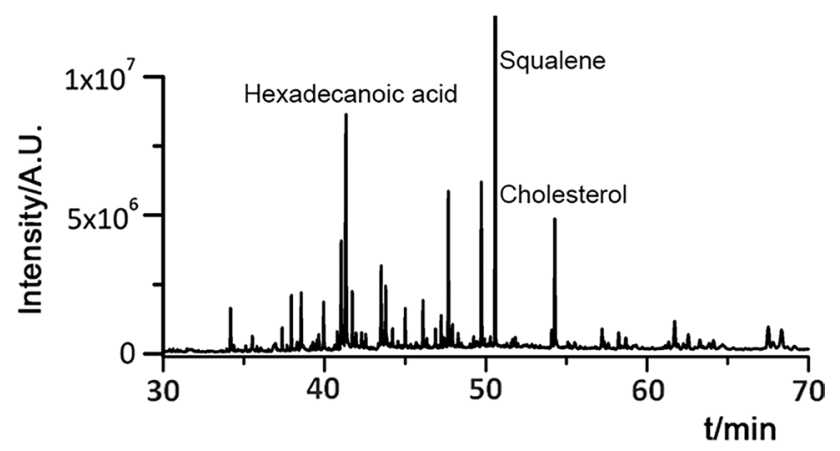

Fig. 4 Total ion current chromatogram of the pre-concentrated extract of a real scent sample from glass beads into ethanol (the extraction procedure is described in "Real samples", the pre-concentration was conducted using evaporation at reduced pressure (approx. $100 \mathrm{mbar}$ ), and the measurement was done under optimized conditions (see "Instrumentation")) the ethanol solvent was evaluated as more appropriate than the hexane solvent for the future forensic analyses of human scent samples.

Acknowledgements This work was supported by the Ministry of the Interior of the Czech Republic, projects nos. VI20172020075 and VH20182021030.

\section{Compliance with ethical standards}

Ethical statement This study was approved by the Institutional Review Board of Charles University, Prague, Faculty of Science (approval number 2016/28) and complies with the Declaration of Helsinki for Medical Research involving Human Subjects. The recruited volunteers were verbally instructed regarding the sampling method and analysis, and signed an agreement (written consent) regarding the use of his/her scent samples in this experiment. The samples of the volunteers were used for this experiment only and then these samples were destroyed.

Open Access This article is distributed under the terms of the Creative Commons Attribution 4.0 International License (http://creativeco mmons.org/licenses/by/4.0/), which permits unrestricted use, distribution, and reproduction in any medium, provided you give appropriate credit to the original author(s) and the source, provide a link to the Creative Commons license, and indicate if changes were made.

\section{References}

Bernier UR, Booth MM, Yost RA (1999) Analysis of human skin emanations by gas chromatography/mass spectrometry. 1 . Thermal desorption of attractants for the yellow fever mosquito (Aedes aegypti) from handled glass beads. Anal Chem 71:1-7. https:// doi.org/10.1021/ac980990v

Bernier UR, Kline DL, Barnard DR, Schreck CE, Yost RA (2000) Analysis of human skin emanations by gas chromatography/mass spectrometry. 2. Identification of volatile compounds that are candidate attractants for the yellow fever mosquito (Aedes aegypti). Anal Chem 72:747-756. https://doi.org/10.1021/ac990963k

Caroprese A, Gabbanini S, Beltramini C, Lucchi E, Valgimigli L (2009) HS-SPME-GC-MS analysis of body odor to test the efficacy of foot deodorant formulations. Skin Res Technol 15:503-510. https ://doi.org/10.1111/j.1600-0846.2009.00399.x

Curran A, Rabin S, Furton K (2005) Analysis of the uniqueness and persistence of human scent. Forensic Sci Commun 7:1-20

Curran AM, Prada PA, Furton KG (2010) The differentiation of the volatile organic signatures of individuals through SPME-GCMS of characteristic human scent compounds. J Forensic Sci 55:50-57. https://doi.org/10.1111/j.1556-4029.2009.01236.x

de Lacy Costello B et al (2014) A review of the volatiles from the healthy human body. J Breath Res 8:014001. https://doi. org/10.1088/1752-7155/8/1/014001 
DeGreeff LE, Curran AM, Furton KG (2011) Evaluation of selected sorbent materials for the collection of volatile organic compounds related to human scent using non-contact sampling mode. Forensic Sci Int 209:133-142. https://doi.org/10.1016/j.forsc iint.2011.01.010

Doležal P, Kyjaková P, Valterová I, Urban Š (2017) Qualitative analyses of less-volatile organic molecules from female skin scents by comprehensive two dimensional gas chromatography-time of flight mass spectrometry. J Chromatogr A 1505:77-86. https://doi. org/10.1016/j.chroma.2017.04.062

Doležal P et al (2019) Multiplicity of human scent signature. Egypt J Forensic Sci 9:7. https://doi.org/10.1186/s41935-019-0112-z

Dormont L, Bessiere JM, Cohuet A (2013) Human skin volatiles: a review. J Chem Ecol 39:569-578. https://doi.org/10.1007/s1088 6-013-0286-Z

Gallagher M, Wysocki CJ, Leyden JJ, Spielman AI, Sun X, Preti G (2008) Analyses of volatile organic compounds from human skin. Br J Dermatol 159:780-791. https://doi.org/10.111 1/j.1365-2133.2008.08748.x

Haze S, Gozu Y, Nakamura S, Kohno Y, Sawano K, Ohta H, Yamazaki K (2001) 2-Nonenal newly found in human body odor tends to increase with aging. J Invest Dermatol 116:520-524. https://doi. org/10.1046/j.0022-202x.2001.01287.x

Hudson-Holness DT, Furton KG (2010) Comparison between human scent compounds collected on cotton and cotton blend materials for SPME-GC/MS analysis. J Forensic Res 1:1-6. https://doi. org/10.4172/2157-7145.1000101

Kusano M, Mendez E, Furton KG (2011) Development of headspace SPME method for analysis of volatile organic compounds present in human biological specimens. Anal Bioanal Chem 400:18171826. https://doi.org/10.1007/s00216-011-4950-2

Natsch A, Derrer S, Flachsmann F, Schmid J (2006) A broad diversity of volatile carboxylic acids, released by a bacterial aminoacylase from axilla secretions, as candidate molecules for the determination of human-body odor type. Chem Biodivers 3:1-20. https:// doi.org/10.1002/cbdv.200690015

Pandey SK, Kim K-H (2011) Human body-odor components and their determination. Trends Anal Chem 30:784-796. https://doi. org/10.1016/j.trac.2010.12.005
Prada PA, Curran AM, Furton KG (2010) Comparison of extraction methods for the removal of volatile organic compounds (VOCs) present in sorbents used for human scent evidence collection. Anal Methods 2:470-478. https://doi.org/10.1039/B9AY00239A

Prada PA, Curran AM, Furton KG (2011) The evaluation of human hand odor volatiles on various textiles: a comparison between contact and noncontact sampling methods. J Forensic Sci 56:866881. https://doi.org/10.1111/j.1556-4029.2011.01762.x

Prada PA, Curran AM, Furton KG (2014) Human scent evidence. CRC Press, Boca Raton

Schoon A, Haak R (2002) K9 suspect discrimination : training and practicing scent identification line-ups. Detselig Enterprises, Calgary

Stein SE, Linstrom P, Mirokhin Y, Tchekhovskoi D, Yang X (2011) NIST Mass Spectral Search Program (Version 2.0g). Gaithersburg, USA

Syed Z, Leal WS (2009) Acute olfactory response of Culex mosquitoes to a human- and bird-derived attractant. Proc Natl Acad Sci USA 106:18803-18808. https://doi.org/10.1073/pnas.0906932106

Vandendool H, Kratz PD (1963) A generalization of the retention index system including linear temperature programmed gas-liquid partition chromatograhy. J Chromatogr 11:463-471. https://doi. org/10.1016/s0021-9673(01)80947-x

Zeng XN, Leyden JJ, Lawley H, Sawano K, Nohara I, Preti G (1991) Analysis of characteristic odors from human male axillae. J Chem Ecol 17:1469-1492

Zeng XN, Leyden JJ, Spielman AI, Preti G (1996) Analysis of characteristic human female axillary odors: qualitative comparison to males. J Chem Ecol 22:237-257

Publisher's Note Springer Nature remains neutral with regard to jurisdictional claims in published maps and institutional affiliations. 